\title{
Structure-induced equilibrium and legislative choice
}

\author{
KENNETH A. SHEPSLE and BARRY R. WEINGAST \\ Washington University
}

In the area of legislative choice, social choice theorists have focused on the equilibrium properties of pure majority rule (PMR), operating according to the implicit belief that whatever is true about the PMR mechanism also applies to institutions based upon it. This view has encouraged the study of what seemed to be the general case, thereby avoiding the narrower study of special cases such as those that might be observed in prominent real-world legislatures, e.g., the U.S. Congress. Over the past decade, the literature has marched toward increasingly general results about the nearly complete instability of PMR; a very detailed review of these developments is found in Schofield (1980). These results in the context of the operating belief noted above seem to imply that the stability of legislative outcomes is tenuous at best.

In this paper, we develop an alternative view of institutions based upon majority rule and show that PMR is a special subset of this category, if not an extreme special case. By focusing upon the manner in which institutions transform PMR into a different legislative game (such as one with a committee system), we can show the properties of legislative institutions necessary for the existence of equilibrium.

The paper proceeds as follows. In Section I, we briefly review the recent literature on voting that focuses on the instability of majority rule. In Section II, we demonstrate how stability may be induced in appropriate institutional circumstances and illustrate these circumstances with several examples. In Section III, we develop the theory behind these examples, showing the general

Mr. Shepsle is Professor of Political Science and Research Associate at the Center for the Study of American Business, Washington University. Mr. Weingast is Assistant Professor of Economics and Research Associate at the Center for the Study of American Business, Washington University. This paper was stimulated by Tullock's paper, 'Why so much stability?' We would like to thank author Tullock for sending us the early versions of this paper, and editor Tullock for encouraging us to write up our own comments and thoughts. An earlier version was presented at the Annual Meeting of the Public Choice Society, New Orleans, 1981, where it benefitted from wide-ranging discussion. We also greatly benefitted from several conversations with John Ferejohn. 
principle upon which stability is based. Finally, the concluding section draws some general implications and points to what remain, in our opinion, the important categories of unsettled questions.

We have been impelled to write up these ideas by the provocative question raised by Professor Tullock in a recent essay of the same title, viz. 'Why so much stability?' There he confronts the impossibility/instability theorems of PMR with the apparent fact that real-world legislatures exhibit a good deal of stability. Absent from these real institutions are the manifestations of instability and disequilibrium - constantly shifting majorities, endless cycling, policy reversals - that one would expect of a PMR system. He resolves this apparent contradiction, and in turn answers the question he posed. In his view, logrolling and vote-trading (hereafter called 'legislative exchange') reverse the otherwise bleak hopes for PMR implied by a decade's worth of social choice theory. We propose an alternative resolution of this anomaly. In our view, real-world legislative practices constrain the instability of PMR by restricting the domain and the content of legislative exchange. The latter, in our view, is part of the problem (though by no means the only part) with PMR, not part of the solution. Throughout, then, we hope to convey what we believe is a compelling case for answering Tullock's question, 'Why so much stability?' with 'Institutional arrangements do it!' It is the transformation ${ }^{1}$ of PMR into a more complex institutional arrangement, not logrolling and other forms of exchange, that produces 'so much' stability.

\section{Section I: Instability of pure majority rule}

Starting with Plott (1967), students of majority rule have focused on the extreme and special nature of the conditions necessary for the existence of equilibrium; generally no such equilibrium exists. This literature has matured over the past decade and includes the work, among others, of Kadane (1972), Sloss (1973), Kramer (1973), McKelvey (1976, 1979), McKelvey and Wendell (1976), Slutsky (1977), Cohen (1979), Schofield (1978), and Cohen and Matthews (1980). These results are by now quite familiar to readers of this journal and may be summarized as follows. Assume an $m$-dimensional policy space, $X$, of feasible outcomes, and consider choice over $X$ by an $n$-person legislature. The legislature operates under a system of pure majority rule (PMR) in which any legislator (or group of legislators) may make proposals to alter the status quo, $x^{0}$. Any proposal that commands a majority against $x^{0}$ beats it. In this setting, a majority rule equilibrium (MRE) is an element of the feasible set that is unbeaten by any other element of $X$ in paired comparison. The results cited above show that under all but extreme circumstances - specifically, smooth and convex preferences distributed in a precisely symmetrical fashion (see Plott, 1967; McKelvey and Wendell, 1976) - no MRE exists. Rather, for any 
point, $x \in X$, there is a non-empty set of points, $W(x)$, called the majority-rule win set at $\mathrm{x}$, each element of which commands the support of a majority against $x$. The lack of equilibrium implies that for all $x \in X, W(x) \neq \emptyset$. As a consequence, majority rule cycles exist, cycles which can be shown to extend over the entire policy space (McKelvey, 1976, 1979; Cohen, 1978; Schofield, 1978, 1980).

It may be noted, moreover, that no form of legislative exchange can obviate these results as long as the pure majority rule structure is maintained. That is, no form of logrolling, whether implicit or explicit, coalition formation, or individual bargaining, can eliminate the inherent instability that follows from the non-existence of an MRE. No matter what form of exchange is postulated, any point is dominated by some other proposed point that benefits a decisive coalition. For example, suppose some policy $x$ is arrived at through logrolling or coalition formation. Then, because $W(x)$ is non-empty at $x$, the losers, in combination with some of the winners at $x$, may propose some $y \in W(x)$ that makes this new majority better off at $y$ than at $x$. And nothing in the rules of the PMR game prohibits the new majority from forming and displacing its predecessor. This is the very essence of the nonexistence of equilibrium. ${ }^{2}$

The principal features of PMR, and the inefficaciousness of vote-trading in the resolution of disequilibrium, are illustrated in Figure 1. Here we consider the case of a five-person legislature using PMR. Each legislator has strictly quasi-convex preferences (in fact, so-called Type I preferences) and ideal point labeled $\bar{x}^{i}$. For an arbitrary point $x^{0} \in X$, the five petal-shaped shaded regions displayed in the figure constitute the set of points that three or more legislators

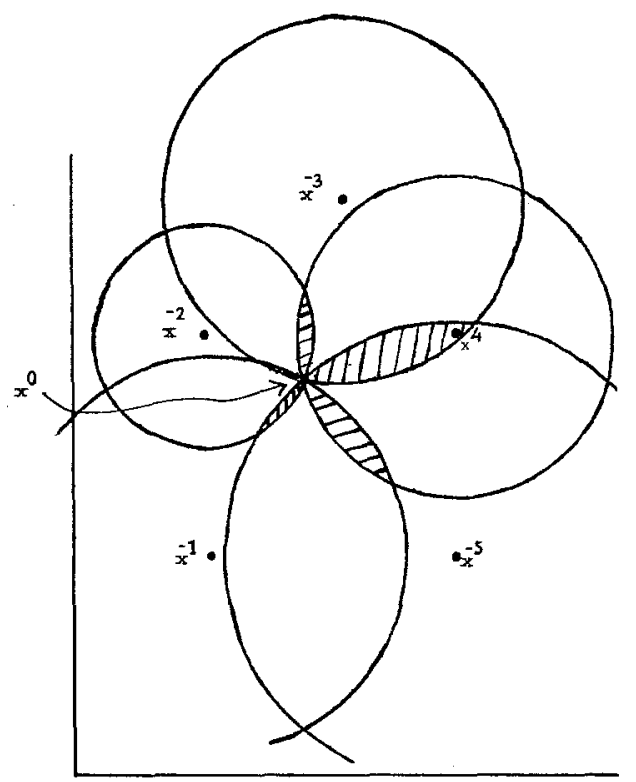

Figure 1. 
prefer to $x^{0}$; that is, their union is $W\left(x^{0}\right)$. The thrust of Plott's theorem is that $W(x) \neq \emptyset$ for all $x \in X$ except possibly for those points (if any) satisfying Plott's extreme symmetry condition. Thus, no point is an equilibrium; the core of the PMR game is empty; and these results remain in force for any legislature of cardinality $n \geqslant 3$ and any issue characterization of dimensionality $m \geqslant 2$.

To make our point most forcefully, let us briefly consider the quintessential logrolling circumstance - the pork barrel. For simplicity we develop a highly symmetric example, though the force of our argument is not compromised by further complexities. Let each legislator in an $n$-person legislature represent a geographical constituency which seeks a pork-barrel project. A project is parametrized by a scalar $-x_{j}$ for the $j$ th district - measuring project size. Thus, an outcome in this context is an $n$-dimensional vector, $\left(x_{1}, \ldots, x_{n}\right)$, describing the various scales at which projects in each of the $n$ districts are to be built. Associated with each project are benefits concentrated exclusively in the district in which the project is sited $-b_{i}\left(x_{j}\right)=0$ if $i \neq j-$ and costs distributed across all districts according to a fixed tax-sharing rule, $t_{i} c\left(x_{j}\right)$ being district $i$ 's $\operatorname{tax}$ burden for district $j$ 's project. The maximand for the $j$ th legislator, assuming here that it is based exclusively on the net benefits secured by his district, is

$$
N_{j}\left(x_{1}, \ldots, x_{n}\right)=b_{j}\left(x_{j}\right)-t_{j} \sum_{i=1}^{n} c\left(x_{i}\right)
$$

If project benefits are increasing at a marginally diminishing rate in project scale $\left(b^{\prime}>0, b^{\prime \prime}<0\right)$ and costs are increasing at a marginally increasing rate $\left(c^{\prime}>0, c^{\prime \prime}>0\right)$, then the level sets of the $N_{j}(x)$ functions are smooth and quasiconvex. The ideal point of the $j$ th legislator is given by the vector $\mathbf{x}^{j}$ in which the $i$ th component is zero for $i \neq j$ and the $j$ th component is the value for which $b_{j}^{\prime}\left(x_{j}\right)=t_{j} c^{\prime}\left(x_{j}\right)$.

That is, the pork-barrel PMR game is the $n$-dimensional version of Figure 1 with each legislator bliss point located along its own dimension so as to satisfy the above first-order condition. Consequently, the generic instability associated with that earlier example applies here as well. The no-project vector, $(0, \ldots, 0)$, is defeated by a coalition $D$ consisting of the collection of $d=\frac{n+1}{2}$ ( $n$ odd) projects, each set at the scale $x_{j}^{*}$ for which $b_{j}\left(x_{j}^{*}\right)>t_{j} \sum_{i \in D} c_{i}\left(x_{i}^{*}\right)$. This vector of projects, in turn, is defeated by the bribe coalition (Fiorina, 1980) consisting of the $n-d$ losers agreeing to build only one of the $d$ previous projects, thereby bribing its legislator into their coalition. In this case, all members of the new winning coalition have diminished their respective tax burdens by this move. Finally, coming full circle, the no-project vector defeats the bribe vector by a vote of $n-1: 1$.

The point here is that there is no natural stopping point for this choice institution so long as losers are not denied access to the agenda. And it does 
not matter that, as Tullock points out, the efficient policy that builds all projects at their most efficient scale, $x^{e}$, yields legislators highest ex ante payoffs. ${ }^{3}$ Since at any proposal the majority win set is non-empty, it is always in the interests of those who prefer elements of this set to the original point to propose them. And, since nothing in the rules prevents them from doing so, they will. All we wish to note at this point is that $x^{e}$, like any other point under PMR, has a non-empty win set: $W\left(x^{e}\right) \neq \emptyset$. It is therefore vulnerable and holds no privileged theoretical status under PMR. We would, however, distinguish this argument from another entirely different argument, namely that $x^{e}$ might comprise the basis of an ex ante agreement among legislators to alter institutional rules in order to guarantee $x^{e}$ as the outcome. This latter argument, which may well be what Tullock has in mind, involves transforming PMR into a different legislative game, namely one constrained by prior agreements on rules (see note 1).

This transformation differs from logrolling and other forms of legislative exchange within PMR. Consequently, we must further emphasize in this context, since Tullock makes so much of it in his paper, that logrolling accomplishes nothing. If projects are voted on one at a time, in non-cooperative fashion, then any such project will lose $n-1: 1$ and the outcome is the zero vector, $x^{0}$. Logrolling, either of the explicit form in which an omnibus of projects is voted on or of the implicit form in which, through vote-trading agreements, individual projects are approved, provides no new opportunities for equilibrium. As Kadane (1972) demonstrated, either the zero vector is an equilibrium or none is; and, since $W\left(x^{0}\right) \neq \emptyset$, the latter is true. Indeed, what this suggests is that logrolling and other forms of legislative exchange destroy, not enhance, the possibility of equilibrium. We conclude, consequently, that the promising direction of research involves an examination of transformations of the PMR game, transformations that constrain the prospects of logrolling, not enhance it. To this endeavor we now turn.

\section{Section II: Inducing stability}

The multidimensional formulation above, as well as its specialization to the pork barrel, covers a muititude of sins associated with PMR. We have suggested above, moreover, that legislative exchange cannot rescue PMR from disequilibrium and may, in fact, exacerbate the instability. In this section, we show that institutional modifications of PMR may induce stability. Specifically, we show that institutional restrictions on the domain of exchange induce stability, not legislative exchange per se. To see how this works, note that though at all points $W(x)$ is non-empty, if at some point $y$, the rules of the game prohibit proposals in $W(y)$ from being placed on the agenda, or at least prohibit the would-be gainers from making these proposals, then $y$ may 
remain invulnerable or stable. This is not because there do not exist points that beat $y$ but rather because those favoring these points cannot place them on the agenda for consideration.

Example 1: In this first example, we illustrate our point through a set of stringent restrictions on the proposal mechanism; other examples allow for more realistic sets of restrictions. Consider the following modifications to the PMR pork-barrel choice institution in a five-person legislature. Suppose that the decision to build projects is made by majority rule vote between the status quo vector, $x^{0}=(0,0,0,0,0)$, and an omnibus proposal that is put together in the following manner. Any legislator that wishes his project built may simply elect to add it to the omnibus without prior approval of other legislators, providing it is proposed at the efficient scale, $x_{i}^{e}$ (see note 3 ). In this case, the agenda facing the legislature is fixed and the amendments extremely proscribed, allowing only a majority rule comparison between the vector $x^{e}$ and the status quo. All legislators are better off under the omnibus than under the status quo (assuming an even distribution of tax burdens, since $b_{i}>c_{i}$ at $x_{i}^{e}$ ); therefore this beats the status quo. Moreover, since no amendments are allowed, this point remains invulnerable. Even though there exists a large collection of policies that command the support of a majority against this point, they cannot arise for a vote and therefore cannot replace the entire package. Put differently, because the ability of a subset of individuals to logroll is attenuated, they cannot upset this equilibrium as under PMR. As a result of the institutional structure circumscribing individual proposal power, stability is induced.

Example 2: Consider another modification of the pork-barrel example suggested by Fiorina (1980). Given an initial proposed vector of projects, amendments to this proposal may only be of the following form:

(1) strike a project;

(2) add a project;

(3) substitute one project for another.

Under these amendment control rules, it can be shown that a stable policy choice exists, namely $x^{c}$ - the vector of $d$ cheapest projects (where $d$ is the size of a simple majority). Indeed, Fiorina derives the following proposition:

Proposition: Under the specified rules, the omnibus representing $x^{c}$ is stable:

(1) All expansion amendments fail, 1: $n-1$;

(2) All deletion amendments fail, ${ }^{4} n-d: d$;

(3) All substitution amendments fail, $1: n-1$. 
Stability results here as a consequence of the restrictions on proposal power. At the equilibrium, $x^{c}$, there exists many packages of projects that command a majority against this one. However, because amendments are limited to changing one element of the package at a time, none of these may arise for comparison. Consequently, stability is induced.

In this example the amendment rule permitting changes restricted to a single project does not prohibit exchanges across several moves; it just makes it difficult. While vote trading is not precluded, the functional equivalent of contracts may be costly to formulate and costly to enforce. If, for example, the secret ballot is in use, enforcement may be prohibitive. Collaboration, more importantly, if it manages to develop across projects despite high costs, destabilizes the situation; it renders $x^{c}$ vulnerable, while producing some different outcome which, itself, is vulnerable. Put more constructively, institutional arrangements that attach costs to exchange may induce stability that would otherwise not be forthcoming under PMR.

Example 3 (Tullock, 1967): Here we begin with the general multidimensional case, but add the following modifications to the PMR institution. For any point $x$, no point within a certain distance, $d$, may be placed on the agenda. That is, all points within the ball $D(x)$ of radius $d$ around $x$ are not feasible; a presiding officer may rule any such motion dilatory and, therefore, out of order. This requirement may be thought of as a rule that prohibits what Tullock refers to as 'small changes.' We can show that this limitation on the

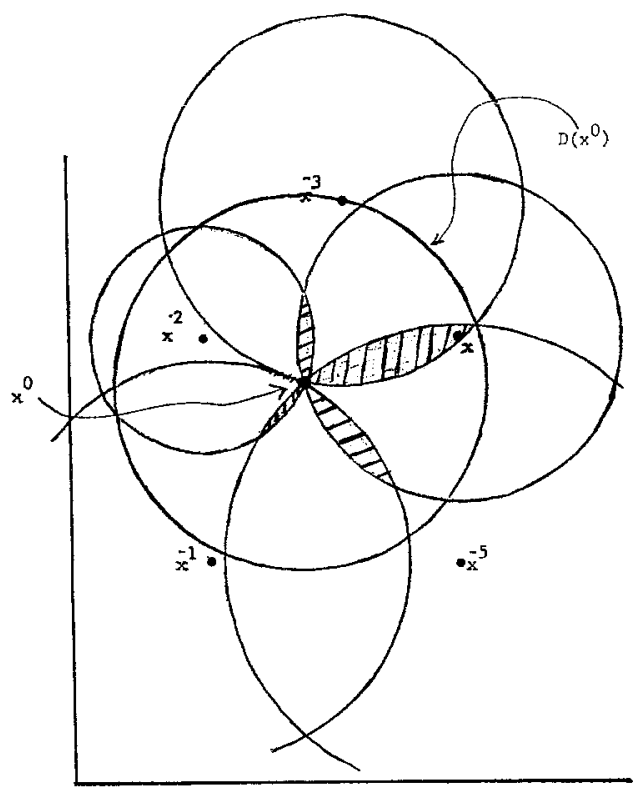

Figure 2. 
ability of members to propose changes may induce stability under certain circumstances. Suppose that $d$ is fixed, and hence for any policy, $x$, we specify the set of infeasible proposals as $D(x)$. If, at some point, $x^{0}$, the majority rule win set, $W\left(x^{0}\right)$, is wholly contained within $D\left(x^{0}\right)$, then $x^{0}$ is invulnerable in the sense that none of the points that command a majority against $x^{0}$ may arise for a vote. Because of this added institutional detail proscribing 'small changes,' $x^{0}$ remains a stable choice. This is illustrated in Figure 2. Figure 2 is identical to Figure 1 with the heavily outlined circle $D\left(x^{0}\right)$ superimposed. It is quite transparent that $x^{0}$ is stable (though the radius of $D\left(x^{0}\right)$ in this particular example may not satisfy some as proscribing 'small' changes inasmuch as it contains nearly the entire Pareto set). It should also be apparent that, for any fixed radius $d$, the existence of equilibrium points depends on the configuration of preferences. If the ideal points of legislators 4 and 5 , for example, were placed at somewhat more southeastern locations in Figure $2, x^{0}$ would no longer be invulnerable, even though 'small changes' were proscribed. More generally, for any given $d$ there appear to be no obvious conditions that guarantee $W(x) \subseteq D(x)$ for some $x .^{5}$

Example 4 (McKelvey, 1979): Social choice theorists have long noted the potential of an 'agenda setter' or convenor for manipulating the final outcome. Several scholars study examples of this type (Plott and Levine, 1978; Issac and Plott, 1979; McKelvey, 1979; Miller, 1979; Romer and Rosenthal, 1979; and Weingast, 1981). It is now well known that under unlimited agenda control by one individual (or set of perfectly conspiring individuals) an agenda may be devised the final outcome of which is his ideal point. In Figure 1, for example, where individual 1 has complete agenda power and no other individual may make proposals, there are no restrictions on individual 1's ability to achieve any desired point. There exists a particular sequence of motions, commencing with $x^{0}$ and ending with $\bar{x}^{1}$, with the property that each motion defeats its predecessor by a majority. Here again, even though the majority win set is non-empty (i.e., $W\left(\bar{x}^{1}\right) \neq \emptyset$ ), none of the legislators preferring elements of this set may propose them. The only one with the power to do so, legislator 1 , has no incentive to do so.

Example 5 (Shepsle, 1979): In our final example, we again modify the fiveperson legislature of Figure 1. Suppose, instead of the unlimited proposal power of each individual, that legislators were restricted to proposing alternatives that change only one dimension of the status quo at a time. No restrictions are placed on the number of amendments nor on which individuals may propose alternatives. Under these circumstances, it can be proved that the vector of medians is an equilibrium. Here again, even though there remain many policies that beat this point, these may not be achieved because of the nature of the restrictions on changes in policy. This is illustrated in 


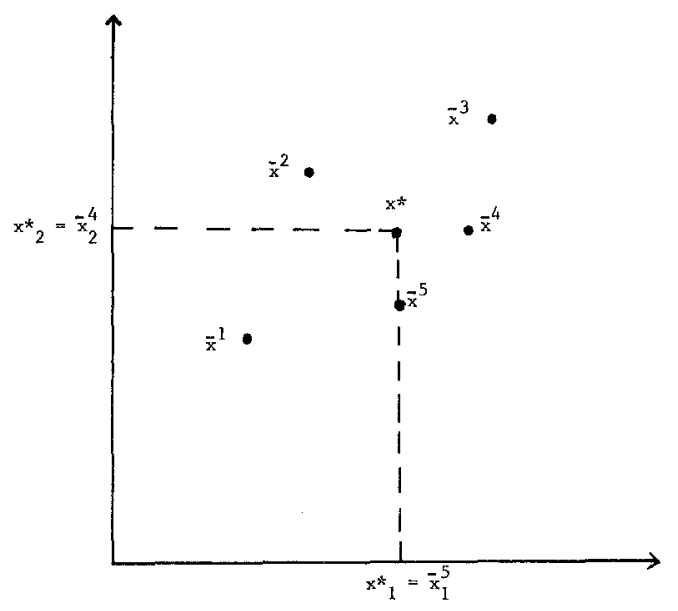

Figure 3.

Figure 3. Here, all proposals that change only one component of $x^{*}$ $=\left(x_{1}^{*}, x_{2}^{*}\right)$, where $x_{i}^{*}$ is the median position along dimension $i$, are dominated by $x^{*}$. As we noted at the end of Example 2, vote-trading agreements across dimensions may allow sophisticated players to subvert $x^{*}$ in favor of some other $y$. It, in turn, is vulnerable to still other points. Hence, this form of logrolling is destabilizing and surely cannot constitute an answer to Tullock's question, 'Why so much stability?'

\section{Section III: Equilibrium in a class of legislative institutions}

The examples of the previous two sections may be summarized as follows. The results by McKelvey et al. show that for any PMR institution, $W(x)$ is nonempty for all $x$. As a consequence, all policies are vulnerable and hence unstable under PMR. The lack of restrictions on the ability of the losers at $x$ to place alternatives before the legislature account for this inherent instability. However, the five examples of the previous section show that restrictions on the ability of individuals or groups to make proposals is one fundamental way in which institutions may induce stability. This is not because the results of McKelvey et al. are irrelevant, but because of the way in which restrictions on proposals neutralize the destabilizing effect of non-empty $W(x)$ sets. In order to understand this kind of stability, therefore, we must look at those features which systematically transform PMR into an institution with appropriate restrictions on the proposal power of individuals. In this sense, the instability of majority rule hinges upon the unrestricted richness of coalition and logrolling possibilities under PMR. Institutions different from PMR may exhibit stability 
precisely because they restrict logrolling behavior and therefore the potential for legislative exchange to upset an equilibrium.

Consider a legislature with $n$ members. Let $C(x, y)$ be the majority rule choice function, i.e., $x=C(x, y)$ iff the number of legislators preferring $x$ to $y$ exceeds the number preferring $y$ to $x$. As before, the majority rule win set at any point $x$ is $W(x)=\{y \mid y=C(x, y)\}$. In a PMR institution, there are no restrictions on proposal or agenda power. The search for equilibrium in past research consequently focused upon $W(x)$. Little explicit attention needed to be given to the set of feasible proposals since this set always comprised the entire space. However, a wide class of institutions based upon majority rule, including the examples offered in Section II, may be described in terms of restrictions on proposal sets available to individuals (or particular sets of individuals). Indeed, we formalize this by defining the family of majority rule legislative institutions.

For any coalition, $s$, composed of one or more members, let $g_{s}(x)$ be the set of feasible points open to $s$ to propose at a given point $x$. These sets capture the idea that some institutions single out different roles for institutional actors, and that the behavioral discretion of these roles may be dependent upon the prevailing state, $x$. For example, in the extreme case of some individual, $i$, with complete agenda power, then $g_{i}(x)=X \forall x$ and $g_{j}(x)=\emptyset \forall j \neq i$ and $\forall x$. In a similar manner, we may define an institution that delegates agenda power to a specific subset or committee. Other examples include restrictions on amendment possibilities, such as a germaneness rule, or on the structure of the order of vote, such as a rule requiring that the status quo be voted upon last.

In addition to knowing the opportunities available to $s$ at any point $x$, it is convenient to know whether $s$ has an incentive to make proposals at this point, that is, whether the members of $s$ prefer some element in $g_{s}(x)$ to $x$. Let these points be $P_{s}(x)$, where $P_{s}(x)=\left\{y \in g_{s}(x) \mid y\right.$ preferred to $\left.x \forall i \in s\right\}$. In the case where $s$ consists of a single legislator $i$, then $P_{i}(x)$ $=\left\{y \in g_{i}(x) \mid U^{i}(y)>U^{i}(x)\right\}$.

Definition: A point $x$ is vulnerable iff $\exists y$ such that

(i) $y \in P_{s}(x)$ for some $s$, and

(ii) $y \in W(x)$.

Otherwise, a point is said to be invulnerable.

We are now in a position to define our notion of equilibrium.

Definition: A point $x^{*}$ is a structure induced equilibrium (SIE) iff it is invulnerable (Shepsle, 1979a, 1979b).

Thus, $x^{*}$ is a SIE iff $W\left(x^{*}\right) \cap P_{s}\left(x^{*}\right)=\emptyset \forall s$. This says that a point $x^{*}$ is an SIE if and only if those points which defeat $x^{*}$ either can be proposed only by those who do not prefer to do so, or cannot be proposed at all. Conversely, if this 
intersection were non-empty, then $x^{*}$ could not be an equilibrium since there remain points which some $s$ is empowered and disposed to propose and which, in turn, are capable of defeating $x^{*}$. Since $s$ could do better in this case, $x^{*}$ cannot be an equilibrium.

The concepts of vulnerability and structure-induced equilibrium define in a precise manner the notion of stability exhibited in the examples in Section II. Within this framework, we may easily see why there are no structure-induced equilibria for PMR. Since the proposal set of all legislators is the entire set at any status quo, there are no restrictions on the ability of individuals who prefer elements of $W(x)$ from proposing them. That is, at any $x, g_{i}(x)=X$ for all $i$. Moreover, at any $x$, there exists an $i$ such that for some $y \in W(x)$, $U^{i}(y)>U^{i}(x)$ so that $W(x) \cap P_{i}(x) \neq \emptyset$. Since this intersection property holds at all $x$, we have shown that no SIE exists for PMR.

However, we may demonstrate, through a series of examples, the usefulness of this approach for studying legislative voting institutions other than PMR. These contrast with the so-called Chaos Theorem of McKelvey et al., inasmuch as the rules limit the set of feasible alternatives to which the status quo is vulnerable.

In our first example, we show the implications of a convenor with exclusive power over the agenda; that is, the only feasible replacements for the status quo are those proposed by him. The situation can be seen in Figure 1 for the status quo, $x^{0}$, with Mr. 2 assumed to be the convenor. $W\left(x^{0}\right)$, representing all the points that command a majority against $x^{0}$, is given by the shaded petals. Yet, only those proposed by the convenor may arise for a vote. The convenor will structure a sequence of votes that leads to his ideal point, $\bar{x}^{2}$. The nonemptiness of $W\left(x^{0}\right)$ guarantees this possibility. ${ }^{6}$ The convenor's ideal point, $\bar{x}^{2}$, is a structure-induced equilibrium, even though $W\left(\bar{x}^{2}\right)$ is non-empty. This is because the set of points preferred to $\bar{x}^{2}$ by the convenor is empty $P_{2}\left(\bar{x}^{2}\right) \cap W\left(\bar{x}^{2}\right)=\emptyset$, so that even though there exist points that beat $\bar{x}^{2}$, these will never arise for a vote.

We next study several rules employed in the U.S. Congress to illustrate restrictions on legislative choice:

(a) The status quo voted on last: This rule means that no matter where votes on alternatives prior to the last one move through the space (by McKelvey, this process can lead anywhere), the last vote is against the prevailing social state, $x^{0}$. Hence, the only outcomes of this process are $x^{0}$ or some point in $W\left(x^{0}\right)$. It will be the latter if the penultimate survivor in the process is in $W\left(x^{0}\right)$; otherwise, it will be the former. Referring back to Figure 1, PMR as amended by the rule of voting the status quo last is a restricted and well-behaved decision process, in which the final result is contained in the shaded area $W\left(x^{0}\right)$. In contrast, the results on PMR by McKelvey imply that the final outcome could lie in any region of the space. 
(b) Committee proposal power: In the House of Representatives, committees (with minor exceptions) initiate the proposal process within their respective areas of policy jurisdiction. The rules of the House require that in addition to voting the status quo last, a committee proposal, $B$, is voted on second to last. This implies that any successful amendment, $A$, to $B$ must satisfy two conditions: (i) $A \in W(B)$; and (ii) $A \in W\left(x^{0}\right)$. The first is necessary if $A$ is to defeat $B$ in the penultimate vote. The second is necessary if $A$, having defeated $B$, is to prevail against $x^{0}$. We have previously seen that voting the status quo last restricts outcomes dramatically. We now learn that granting a committee the power to propose the penultimate alternative further constrains the process; the set of final outcomes now consists of $W\left(x^{0}\right) \cap W(B)$.

(c) Rules Committee: In the House of Representatives, each bill must go to the Rules Committee after being passed by its committee but before it reaches the House floor. The purpose is to grant the bill a 'rule' governing debate and the amendment process. If a rule is not granted, the bill is effectively killed since it may not be forwarded to the full House for a vote. In the days of Judge Smith, autocratic chairman of the House Rules Committee, this veto power was exercised with some frequency. It is clear that this institutional feature further restricts the outcomes of an institutionalized majority rule system. Specifically, to avoid a Rules Committee veto, a committee bill must be contained in the Rules Committee 'preferred to' set, i.e., $B \in P_{R}\left(x^{0}\right)$.

Like institutional practices (a), (b), and (c) above, other features in current use in the legislative process are amenable to similar analyses, including: conference committee agreements, the executive veto, germaneness rules, rules of recognition, and so on. The point of these examples discussed above is to show that the rules employed by legislatures significantly restrict the potential outcomes of the legislative process. Our model provides a technology for studying these effects. The somewhat startling conclusion, in contrast to the McKelvey results that anything may happen, is that the number of potential replacements for a given status quo may be restricted. The reason is simple. Even though the majority rule win-sets are everywhere non-empty, the rules of the legislature may prohibit elements of this set from arising for comparison, thus leaving other points invulnerable.

\section{Section IV: Conclusion}

Professor Tullock has raised a central question in the confrontation between abstract models of PMR and majority rule as practiced in real institutions. We believe the decision máking stability of real-world legislatures lies in the way these legislatures institutionalize majority rule. Logrolling, vote trading, coalition formation, and bargaining are red herrings in this argument. Rather, 
it is the restrictions on such legislative exchange that promote structureinduced equilibrium. Put differently, institutional arrangements place constraints on the completeness of the majority rule relation by restricting social comparisons.

The framework developed here shows that an assumption implicit in the discussions of many majority rule theorists fails to hold. In part, the implicit rationale for focusing upon PMR was that results proved for this rule were presumed to hold for any institution based on PMR. In one sense this remains true, namely, that the majority rule win sets, $W(x)$, are everywhere non-empty. In another sense, however, it is not true that all properties of institutions based upon majority rule are inherited from PMR. The theory outlined above shows that stability may not be as elusive as theorists of PMR have concluded.

The concept of equilibrium developed in the last section incorporates the major features of prominent choice institutions as well as capturing the special cases in the literature cited in Section II. We now turn to a brief discussion of future work. We address the question that remains, in our opinion, the salient one in the study of institutions and their effect on policy choice, namely, understanding the factors governing the choice of one institutional arrangement over another.

Throughout this paper, we have distinguished agreements that transform the rules from agreements (or vote-trades) that take place within a given set of rules. In principle, anything attainable under the former could also be attained under the latter if there were some form of mechanism to enforce vote-trades as contracts. Under such a rubric, complex legislative agreements in the form of contingent contracts achieve the desired result without resorting to the institutionalization of a rule. In practice, however, there are several problems with vote-trading agreements as contracts. First, the cost of writing these contracts is often quite high due to the number of potential contingencies for which provision must be made. Second, and more important, PMR lacks an enforcement mechanism. Individual parties to contracts in market settings have recourse to the courts. This provides protection beyond the assurance of good faith and brand names. No comparable institution exists within the legislature to supplement the natural though imperfect brand name phenomenon (i.e., that of 'keeping one's word' to preserve and enhance credibility for future trades).

While the legislature could create a court or committee to monitor contracts and enforce agreements, alternatively, it could simply impose a rule binding upon everyone which insured the outcome sought. Of the two alternative institutions, the latter probably economizes on transaction costs, particularly for those situations that recur with some frequency. With a rule, a new contract need not be negotiated each time between new sets of players. Moreover, a contingency clause might easily be appended to a rule to cover cases where there is widespread agreement that it is inappropriate. For 
example, in the Congress a special majority may vote to suspend the rules (note that if only a simple majority were required, then this would be no different from PMR). ${ }^{7}$ In sum, logrolling solutions to the problem of forging agreements are unworkable because they lack enforcement mechanisms. Logrolling, then, cannot constitute an answer to the question, 'Why so much stability?'

If institutional rules are to constitute an answer to Tullock's stability question, then we must confront the manner in which those rules are chosen. There are very few theories about the choice of rules - exceptions include Buchanan and Tullock (1962), Buchanan $(1975,1979)$, and contributions in the property rights literature. Even in the absence of a theory, we may still worry that constitutional choice processes (the choice of rules) are vulnerable to the same instabilities found in PMR. We term this the 'Riker Objection' since this issue was recently posed by Riker (1980). If institutional constraints create equilibrium - that is, if transformations of a PMR institution into a non-PMR institution create a situation of equilibrium from one without an equilibrium - then preferences over outcomes lead naturally to an induced set of preferences over institutional arrangements. In this sense, an individual prefers one institution over another if he prefers the equilibrium policy state of one over the equilibrium (or unpredictability) of the other. In the case of multiple equilibria, an individual prefers the institution that yields the highest expected utility given a probability distribution over equilibrium states (Plott, 1972).

As long as preferences for policy states differ, then preferences over institutions with differing equilibrium states (distribution of equilibria) should also differ. The Riker Objection suggests that a simple extension of McKelvey's Chaos Theorem predicts endless cycles here so long as PMR governs the choice over institutions. In this sense, the existence of institutions and their stability must remain, like policy choices under PMR, tenuous what Riker calls 'unstable constants.' Nevertheless, empirically we observe institutions persisting for long periods; in light of the Riker Objection, Tullock's question applies at this level as well.

We may make several observations that imply an attenuation of endless cycling at the institutional-choice level. First, typically, non-PMR rules govern the choice of new rules. Second, it is risky to attempt to change the status quo contrary to the interests of those currently in control. Since failure may lead to the imposition of sanctions, expected gains must be weighed against the certainty of these sanctions. While this does not rule out changes, it will reduce the number of attempts. This is surely the conclusion to be drawn from a reading of the history of the U.S. Congress. The comparison between choice in this setting and the McKelvey world, then, is not parallel since proposals are costless to make in the latter but not in the former. Finally, there often exists a well-defined status quo alternative. In the case of the social 
contract, the status quo is the Hobbesian state of nature. For the case of the U.S. Constitutional Convention, it was the Articles of Confederation (Riker, 1979). In these and similar settings, even though there may be no formal rule that the status quo must literally be voted last, this restriction nevertheless may hold de facto. Consequently, the constitutional outcome is either the status quo ante or an alteration that cannot be vetoed, i.e., an element in the 'win set' of the status quo. With these qualifications in mind, the effect of the Riker Objection is mitigated. Even at the constitutional level, then, restrictions on the ability of individuals to make proposals may induce equilibrium.

\section{NOTES}

1. We wish to distinguish legislative exchange as it occurs in a particular institutional context for example, vote-trading and logrolling in support of a specific bill -from that which occurs in the process that transforms one institutional arrangement into another. As we shall demonstrate, legislative exchange in these two contexts have different effects. We defer until the final section a discussion of legislative exchange in the process transforming PMR into a more complex institutional arrangement.

2. There are illustrations in the literature, e.g., Vickrey's 'self-policing property,' of circumstances in which players entertain rational expectations about continued play. Various conceptions of sophisticated behavior contain this idea as well. With this idea, it is possible to construct contingencies in which the expectation of adverse consequences if the game is permitted to continue induces an aversion to change (continued cycling) by a decisive set of players. It is doubtful, however, whether Tullock's condition of 'so much' stability can be accounted for in this fashion.

3. The efficient vector is $x^{e}=\left(x_{1}^{e}, \ldots, x_{e}^{n}\right)$, where $x_{j}^{e}$ satisfies the first-order condition $b_{j}^{\prime}\left(x_{j}^{e}\right)=c^{\prime}\left(x_{j}^{e}\right)$. For details, see Weingast (1979) and Shepsle and Weingast (1981). In these papers, as well as in Tullock (1981), it is shown that the certainty of $x^{e}$ is preferred by all legislators to the expected value of net benefits on the assumption that some minimal winning coalition will ultimately form, each equally likely.

4. Fiorina's proposition is not quite right in this particular instance inasmuch as it is not at all clear why $d-1$ of the members of the winning coalition oppose striking the project of the remaining coalition member. With one fewer project, their tax burdens all would be reduced. Fiorina notes, however, that he has some form of sophisticated behavior in mind (see note 2 above) according to which members of the winning coalition rationally expect (fear) the strategy of 'striking a project' to be a ploy to destroy the winning coalition; they therefore oppose it.

5. Schofield (1978) gives some analytical precision to a related problem - namely a demonstration of instability in the context in which only small departures from an existing state (incrementalism) are permitted.

6. McKelvey (1977) actually has designed an algorithm by which to accomplish this result.

7. This is the same rationale that underpins the Uniform Commercial Code and other areas of the law of contracts. To cover situations that occur quite regularly, certain standard procedures are written into the law and are automatically a part of any agreement or exchange. This significantly lowers transaction costs (contracts need not be negotiated sui generis), and in those circumstances where the standard is inappropriate, the parties may simply contract around it. Similar results occur in most areas of the common law. For further discussion, see Posner (1976).

8. This reasoning justifies our separation throughout the text of choices within a given institution 
and choices among institutions. This distinction is a natural one, dating back to Buchanan and Tullock's The Calculus of Consent. There they analyze separately the constitutional calculus of choice over voting rules and the behavior under a specific voting rule.

\section{REFERENCES}

Buchanan, J. M. (1975). The limits of liberty. Chicago: University of Chicago Press.

Buchanan, J. M. (1979). What should economists do? Indianapolis: Liberty Press.

Buchanan, J. M., and Tullock, G. (1962). The calculus of consent. Ann Arbor: University of Michigan Press.

Cohen, L. (1979). Cyclic sets in multidimensional voting models. Journal of Economic Theory 20: $1-12$.

Cohen, L., and Matthews, S. (1980). Constrained Plott equilibria, directional equilibria, and global cycling sets. Review of Economic Studies 47: 975-986.

Fiorina, M. P. (1980). Legislative facilitation of government growth: Universalism and reciprocity practices in majority rule institutions. Research in Public Policy Analysis and Management 1: forthcoming.

Isaac, R. M., and Plott, C. R.(1978). Cooperative game models of the influence of the closed rule in three person majority rule committees: Theory and experiments. In P. C. Ordeshook (Ed.), Game theory and political science. New York: New York University Press. 283-322.

Kadane, J. B. (1972). On division of the question. Public Choice 13: 47-55.

Kramer, G. H. (1973). On a class of equilibrium conditions for majority rule. Econometrica 41: 285-297.

McKelvey, R. D. (1976). Intransitivities in multidimensional voting models and some implications for agenda control. Journal of Economic Theory 12: 472-482.

McKelvey, R.D. (1977). Constructing majority paths between arbitrary points. Paper delivered at American Economic Association Meetings. New.York.

McKelvey, R. D. (1979). General conditions for global intransitivities in formal voting models. Econometrica 47: 1085-1111.

McKelvey, R. D., and Wendell, R. E. (1976). Voting equilibria in multidimensional choice spaces. Mathematics of Operations Research 1: 144-158.

Miller, G. J. (1979). Experimental results in two-party agenda setting: What's it worth to be a party? Working paper. Michigan State University.

Plott, C. R. (1967). A notion of equilibrium and its possibility under majority rule. American Economic Review 57: 787-806.

Plott, C. R. (1972). Individual choice of a political-economic process. In R. G. Niemi and H. F. Weisberg (Eds.), Probability models of collective decision making. Columbus: Charles E. Merrill Publishing Co. 83-101.

Plott, C. R., and Levine, M. E. (1978). A model of agenda influence on committee decisions. American Economic Review 68: 146-160.

Posner, R. A. (1977). Economic analysis of law. 2nd Edition. Boston: Little-Brown.

Riker, W. H. (1979). The verification of scientific generalizations by historical case studies: The genesis of the American Constitution. Presented at Meeting of Social Science History Association. Cambridge, Mass.

Riker, W. H. (1980). Implications from the disequilibrium of majority rule for the study of institutions. American Political Science Review 74: 432-447.

Romer, T., and Rosenthal, H. (1978). Political resource allocation, controlled agendas, and the status quo. Public Choice 33: 27-45.

Schofield, N.(1978). Instability of simple dynamic games. Review of Economic Studies 45: 575-594.

Schofield, N. (1980). Formal political theory. Quality and Quantity 14: 249-275. 
Shepsle, K. A. (1979a). Institutional arrangements and equilibrium in multidimensional voting models: American Journal of Political Science 23: 27-59.

Shepsle, K. A. (1979b). The role of institutional structure in the creation of policy equilibrium. In D. W. Rae and T. J. Eismeier (Eds.), Public choice and public policy. Beverly Hills: Sage. 249283.

Shepsle, K. A., and Weingast, B. R. (1980). Political solutions to market problems: The political incidence of economic benefits and costs. Delivered at Meetings of Public Choice Society. San Francisco.

Shepsle, K. A., and Weingast, B. R. (1981). Political preferences for the pork barrel: A generalization. American Journal of Political Science 25: 96-112.

Sloss, J. (1973). Stable outcomes in majority rule voting games. Public Choice 15: 19-48.

Slutsky, S. M. (1977). A voting model for the allocation of public goods: Existence of an equilibrium. Journal of Economic Theory 14: 299-325.

Tullock, G. (1967). The general irrelevance of the general impossibility theorem. Quarterly Journal of Economics, May 1967, p. 256. Reprinted in Towards a mathematics of politics, 1967, University of Michigan Press, Ann Arbor, Michigan, p. 37.

Tullock, G. (1981). Why so much stability? Public Choice 37: 189-202.

Weingast, B. R. (1979). A rational choice perspective on Congressional norms. American Journal of Political Science 24: 245-263.

Weingast, B. R. (1981). Regulation, reregulation, and deregulation: The political foundations of agency-clientele relationships. Law and Contemporary Problems 44: 147-177.

\section{EDITOR'S NOTE}

The debate is still open. Further papers on this subject are welcomed. The author of 'Why so much stability?' will be given an opportunity to reply in a later issue to all of the comments. 